screening of well women for the deteotion of early malignant and pre-malignant conditions of the cervix has recently become accepted as a valid measure of preventive medicine in this country and a massive training programme for technicians was initiated. The need for textbooks on the subjeot became very apparent and few people can be better qualified to fill this gap than the author of this book.

This textbook was first published in 1964. The author states that the text is meant as an introduction to the subject to those who wish to acquaint themselves with the techniques and with the basic principles involved; it does not claim to be a reference book. As an introduotion, it is a remarkably lucid statement. The first two chapters deal with techniques of smear taking and with staining techniques. The three following chapters deal with normal smear patterns and give an outline of endocrine cytology. The author's wide experience is reflected here in the critical view of the applications as well as of the limitations of the method. The chapter on the diagnosis of malignancy is relatively brief but extremely cogent. A comprehensive bibliography, which is referred to in the text, is included at the end of the book. A large number of photomicrographs illustrate the text, but these are not all of a uniformly high standard.

This short book sets out very adequately guide lines for practitioners in the field; it offers an excellent, albeit brief, presentation of the subject and can therefore be strongly recommended to gynaecologists and to general medical readers.

\section{An Outline and Atlas of Gynaecological Cytodiagnosis}

By H. D. Smolka, and H.-J. Soost. Pp. 208, illustrated. London: Edward Arnold. 1965. £6.

This textbook is a welcome addition to the very limited number of authoritative reference books which exist on a subject which is rapidly gaining in interest and topicality in this country.

The book amply fulfils the dual purpose implied in its title. As an atlas it contains a large number of illustrations, many of them in colour, which are of an extremely high standard throughout. The presentation of the text in the chapters dealing with endocrine cytology reveals at all times the critical judgment of the authors. "The limitations of cytological hormone diagniosis must be recognised. They are mainly due to the limited manner in which the vaginal epithelium can react in response to different hormonal stimuli." This statement may be selfevident, but cannot be overemphasised. An equally cautious approach is reflected in the rather brief section of the book which deals with the diagnosis of malignancy. This reviewer likes the nomenclature chosen by the authors who use the term "atypical cells" as meaning cells suspected of malignancy; "such cells may originate from a malignant process, from a carcinoma in situ or from a dysplastic area" and "their presence generally only allows a probable diagnosis and never a definite diagnosis of cancer" (p. 142). Two points appear to be implied in these passages - first, the recognition of the subjective element in the diagnosis of malignancy of cells-a point which is well worth emphasising. This approach could be extended to the recognition of the subjective element in the histological diagnosis of these lesions. The authors however set up histological criteria as absolute arbiters; secondly, a qualitative distinction appears to have been made between a malignant process and carcinoma in situ. It is therefore disappointing to find that the whole subject of carcinoma in situ, its relationship to the dysplasias on one hand, and to invasive growth on the other is treated so briefly as to be almost perfunctory. The confusion which arises in the text when the terms "atypical" and "abnormal" cells are used sometimes synonymously, and at other times as implying different grades of a process is a minor defect. In spite of these objections it must be emphasised that this book offers an excellent and detached presentation of its main subject. The quality of the illustrations is outstanding and the book can be strongly recommended to specialists as well as to the more casual reader.

\section{The Application of Neuroleptanalgesia in Anaeshetic} and Other Practice

Edited by N. W. Shephard. Proceedings of the 1st. British Symposium sponsored by Jansen Pharmaceuticals Division of Ortho Pharmaceuticals Ltd. Edinburgh. June 1964. Pp. ix +96 illustrated. Oxford, London etc.: Pergamon Press. 1965. 50s.

This book is so bad that it has a certain importance. It is an anachronism not only in the sense that at least one of the three drugs it discusses has already been superceded, but because its whole approach to the clinical investigation of new drugs is thirty years out of date. There is scarcely anything in this self-styled symposium which deserves to be called a clinical trial, let alone a controlled trial, and the printed discussion is piffling. The book costs fifty shillings, for less than ninety pages of text with no index, but it would be a waste of money at any price.

Neuroleptanalgesia is a technique of considerable potential value, and the drugs used are of immense interest, but nobody would guess it from this publication. In this respect the manufacturers have been their own worst enemies in sponsoring such an enterprise; yet one wonders just what alternatives were open to them. Many of the difficulties in the current relationship between the drug industry and the medical profession are illustrated by the appearance of a volume of this kind-hence its certain importance.

Drug firms repeatedly affirm that they have no difficulty in obtaining clinical investigators; in a sense this may be true, quantitatively if not qualitatively. It would be unrealistic to imagine that there are not plenty of people in the medical profession, as in every other walk of life, who will readily undertake a task for which some interested party has persuaded them that they are suited. But is not time we stopped paying lip service to the need for good, meaningful, clinical trials and began to set up machinery which would make it possible to undertake them, instead of having to canvass individual doctors and make do with whatever statistical and other "expert" advice happens to be at hand, if any!

The drug industry has large amounts of money available for clinical investigation, and freely admits the fact. Surely some of this money could be pooled 